\title{
PENGGUNAAN METODE SIMULASI GUNA MENENTUKAN JUMLAH TENAGA KERJA KESEHATAN DI INSTALASI RAWAT DARURAT RSUD Dr. SAIFUL ANWAR MALANG
}

\author{
Murti Astuti ${ }^{1}$, Dian Heriani ${ }^{2}$
}

\begin{abstract}
The amount of hospital in a row with increasingly of the society level, 50 level hospital is demanded to diectly fix up and increase the servility system. The servility system very significant in competent to satisfy the patient. One of parameter to eveluate good or bad a servicing system is a patient wait time. This research take a sample at this emergency treatment Installation RSUD Dr. Saiful Anwar Malang. Where the patient that come have to be handled correctly and quickly, because the patient that enter to the Emergency Treatment Installation in IRD must wait too long time will cause physical defect even death. There for this research is intended to analyze patient servicing system, determine the sum the health power, and the sum of maximal patient that can be handled y emergency treatment Installation, so got the wait time that is fit with patient aspiration level.

The procedure that necessary to be done is divided in the several period, First, process the data with Statgraf 5.0 program package to get the coming time distribution of the patient and the patioent servicing time. Second, make the model with use activity diagram after through some simplification. Third, after the model considered already able to present real system, so try to copy the servicing system behavior of emergency treatment installation with use input arena 3.0 program that needed included the sum of health power, the sum of patient coming and simulation time. Fourth the implementation of validity test, fifthly implemate the simulation experiment with change the sun of health power from 10 until 15, the amount of patient with $125,150,200,250$ sixth take the decision criteria to get the waiting time that hoped with use the aspiration level method.

The decision result that got is with simulated with time 2100 second 50 the maximal patient that able to be handled by health power is 200 patient. There for the number of patient under 200 , health power that able to handle is 15 person. So the adding in the amount of 5 health powers, that are 2 doctors to handle this priority 1 patioent, a nurse to handle the checking of priority 2 patient, a nurse to handle the checking of priopity 3 patient, and a doctor to handle the treatment of priority 3 patient.
\end{abstract}

Key Words : patient queuing up, system modeling, simulation

\section{PENDAHULUAN}

Suatu organisasi perusahaan yang bergerak dalam bidang jasa maupun manufaktur akan selalu berusaha untuk mencapai target perusahaan berupa laba yang maksimal atau biaya pengeluaran yang paling minimum. Dalam pencapaian target perusahaan tersebut, tidak terlepas dari pentingnya menerapkan fungsi manajemen yaitu perencanaan, pengorganisasian, pengarahan dan pengawasan. Fungsi perencanaan merupakan salah satu fungsi manajemen yang sangat penting dan harus dilaksanakan sebelum melaksanakan fungsi manajemen lainnya.

Salah satu fungsi dalam sistem produksi yang penting adalah perencanaan agregat dan jadwal induk produksi .Perencanaan produksi agregat dan jadwal 
induk produksi yang baik membuat pelaksanaan produksi akan berlangsung dengan baik pula. Perencanaan produksi agregat bertujuan untuk menyusun suatu rencana produksi untuk keseluruhan produk yang akan dapat memenuhi permintaan dengan menggunakan sumber-sumber atau alternatif-alternatif produksi yang tersedia dengan total biaya yang paling kecil. Sedangkan penjadwalan induk produksi bertujuan menyusun suatu rencana produksi yang terperinci tentang jenis dan jumlah produk yang diproduksi untuk masingmasing jenis produk dalam suatu periode waktu.

\section{Indah Cemerlang adalah} perusahaan yang memproduksi bahan bangunan seperti tegel, paving stone, bataco dan genteng. Dalam melaksanakan proses produksinya $\mathrm{CV}$. Indah Cemerlang berdasarkan pesanan atau job shop. Pada bulan - bulan tertentu perusahaan ini mendapatkan pesanan yang sangat tinggi, misalnya pada bulan pembangunan yaitu sekitar bulan Juli dan Agustus atau waktu menjelang hari raya .

$$
\text { Mengingat sering terjadinya }
$$

fluktuasi permintaan setiap bulan maka diperlukan suatu metode untuk memprediksi fluktuasi tersebut pada periode mendatang. Karena fluktuasi tersebut mengakibatkan sering terjadi penumpukan pada satu jenis produk tertentu sedangkan kekurangan pada jenis produk yang lain. Hal tersebut bisa merugikan perusahaan, penumpukan produk menyebabkan perusahaan harus mengeluarkan biaya penyimpanan, dan pemeliharaan juga resiko perusahaan atas rusaknya produk tersebut sedangkan kekurangan produk mengakibatkan perusahaa tidak dapat memenuhi permintaan konsumen atau pelanggan sehingga mengakibatkan berkurangnya kepercayaan konsumen atau pelanggan terhadap kemampuan perusahaan.

Untuk itu perusahaan harus mempertahankan jumlah persediaan yang optimal agar dapat menjamin terpenuhinya pesanan konsumen, bagi kelancaran kegiatan produksi dalam jumlah dan mutu yang tepat serta biaya yang minimum.

\section{TINJAUAN PUSTAKA}

\section{Model - model peramalan}

\section{Motode peramalan kualitatif}

2. Metode peramalan kuantitatif

Beberapa performans untuk menentukan akurasi hasil peramalan secara kuantitatif antara lain :

1. Mean Error (ME)

$$
\mathrm{ME}=\frac{\sum_{i=1}^{n}(X i-F i)}{n}
$$

2. Mean Absolute Deviation (MAD)

$$
\mathrm{MAD}=\frac{\sum_{i=1}^{n}|X i-F i|^{2}}{n}
$$

3. Mean Square Error (MSE)

$$
\mathrm{MSE}=\frac{\sum_{i=1}^{n}|X i-F i|^{\frac{1}{2}}}{n}
$$




\section{Metode peramalan time series}

\section{a. Moving Average}

Metode moving average dirumuskan sebagai :

$F_{t+1}=$

$\frac{X_{t}+X_{t-1}+\ldots \ldots+X_{t-n+1}}{n}=\frac{\sum_{i=t-n+1}^{t} X_{i}}{n}$

\section{b. Double eksponensial Smoothing}

$$
F_{t}=a_{0}+a_{1} t+e_{t}
$$

Dimana, $\mathrm{a}_{\mathrm{o}}, \mathrm{a}_{\mathrm{e}}$ adalah parameter proses dan e mempunyai nilai harapan dari 0 dan sebuah variansi $\sigma_{e}^{2}$. Misalkan $\beta=1-\alpha$, sehingga :

$F t=\alpha f_{1}+\alpha \beta f_{t-1}+\ldots .+\alpha \beta^{t-1} f_{1}+\beta^{t} f_{0}$

Persamaan diatas dapat dituliskan ulang sebagai :

$$
\mathrm{F}_{\mathrm{t}}=\alpha \sum_{i=0}^{t-1} \beta^{i} f_{t-i}+\beta^{t} f_{0}
$$

Double eksponensial smoothing adalah exponensial smoothing dari single exponensial smoothing, yang dirumuskan sebagai berikut :

$$
\mathrm{Xt}^{(2)}=\alpha \mathrm{Xt}+\beta \mathrm{X}^{(2)} \mathrm{t}-1
$$

\section{c. Metode Peramalan Winters's}

Model Winters's dirumuskan sebagai :

$$
\mathrm{Xt}=(\mathrm{aot}, \mathrm{t}+\mathrm{al}, \mathrm{t}) \mathrm{Ct}+\mathrm{et} .
$$

Dimana $\mathrm{C}$ adalah faktor musiman. $\mathrm{ao}_{, \mathrm{t}}$ al, $t, \mathrm{Ct}$ merupakan parameter yang diupdate secara kontinyu engan menggunakan exponensial smoothing proedure.

$\mathrm{a}_{\mathrm{o}, \mathrm{t}}=\alpha\left(\mathrm{Xt} / \mathrm{C}_{\mathrm{t}-\mathrm{N}}\right)+(1-\alpha)(\mathrm{ao}, \mathrm{t}-1+\mathrm{a} 1, \mathrm{t}-1)$

\section{Memilih model peramalan yang terbaik}

MAPE $=\frac{\left(\sum_{1}^{t} \frac{|\hat{f t}-f t| x 100 \%}{f t}\right)}{n}$

\begin{tabular}{|c|c|c|c|c|c|c|}
\hline \multirow[t]{2}{*}{ Sumber } & \multicolumn{4}{|c|}{ Periode Permintaan } & \multirow{2}{*}{ Dummy } & \multirow[t]{2}{*}{ Kapasitas produksi } \\
\hline & 1 & 2 & 3 & 4 & & \\
\hline Io & 0 & $\mathrm{Ch}$ & $2 \mathrm{Ch}$ & $3 \mathrm{Ch}$ & 0 & Io \\
\hline RT1 & $\mathrm{r}$ & $\mathrm{r}+\mathrm{Ch}$ & $\mathrm{r}+2 \mathrm{Ch}$ & $\mathrm{r}+3 \mathrm{Ch}$ & 0 & Ll \\
\hline OTI & $\mathrm{v}$ & $\mathrm{v}+\mathrm{Ch}$ & $\mathrm{v}+2 \mathrm{Ch}$ & $\mathrm{v}+3 \mathrm{Ch}$ & 0 & $\mathrm{Ml}$ \\
\hline RT2 & $\mathrm{r}+\mathrm{Cs}$ & $\mathrm{r}$ & $\mathrm{r}+\mathrm{Ch}$ & $\mathrm{r}+2 \mathrm{Ch}$ & 0 & L2 \\
\hline OT2 & $\mathrm{v}+\mathrm{Cs}$ & $\mathrm{V}$ & $\mathrm{v}+\mathrm{Ch}$ & $\mathrm{v}+2 \mathrm{Ch}$ & 0 & $\mathrm{M} 2$ \\
\hline RT3 & $\mathrm{r}+2 \mathrm{Cs}$ & $\mathrm{r}+\mathrm{Cs}$ & $\mathrm{r}$ & $\mathrm{r}+\mathrm{Ch}$ & 0 & L3 \\
\hline OT3 & $\mathrm{v}+2 \mathrm{Cs}$ & $\mathrm{v}+\mathrm{Cs}$ & $\mathrm{V}$ & $\mathrm{v}+\mathrm{Ch}$ & 0 & M3 \\
\hline RT4 & $\mathrm{v}+3 \mathrm{Cs}$ & $\mathrm{r}+2 \mathrm{Cs}$ & $\mathrm{r}+\mathrm{Cs}$ & $\mathrm{r}$ & 0 & L4 \\
\hline 0 & $\mathrm{v}+3 \mathrm{Ch}$ & $\mathrm{v}+2 \mathrm{Ch}$ & $\mathrm{v}+\mathrm{Cs}$ & $\mathrm{v}$ & 0 & M4 \\
\hline $\mathrm{Yt}$ & Y1 & Y2 & Y3 & Y4 & 0 & \\
\hline
\end{tabular}

\section{Perencanaan Agregat}

Tabel 1

Matrik Formulasi Masalah Agregat 


\section{METODOLOGI PENELITIAN}

\section{Jenis Data yang Diperlukan}

Data yang diperlukan dalam penelitian ini adalah data-data yang mempunyai kaitan dengan jumlah permintaan, proses produksi, waktu produksi, jam kerja, mesin, serta jumlah produksi.

\section{Tahapan Pengolahan Data}

1. Peramalan Permintaan

2. Perencanaan Agregat

3. Perencanaan Disagregat

4. Kalkulasi Biaya

\section{HASIL DAN PEMBAHASAN}

\section{Peramalan permintaan terhadap prosentase cacat produk}

Hasil perhitungan dengan menggunakan rumus diatas didapatkan jumlah dari tiap - tiap jenis produk yang harus diproduksi selama satu horison perencanaan (12 periode) yang akan datang, seperti yang terlihat dibawah ini :

Cara menghitung prosentase cacat

- Produk Tegel

September $2001=\frac{2294}{1-0.01}=2318$

Oktober $\quad 2001=\frac{2286}{1-0.01}=2309$

November $2001=\frac{2355}{1-0.01}=2379$

Desember $2001=\frac{2346}{1-0.01}=2370$
Januari $\quad 2002=\frac{2416}{1-0.01}=2440$

Februari $2002=\frac{2406}{1-0.01}=2430$

Maret $2002=\frac{2477}{1-0.01}=2502$

April $\quad 2002=\frac{2466}{1-0.01}=2491$

Mei $\cdot 2002=\frac{2538}{1-0.01}=2564$

Juni $2002=\frac{2526}{1-0.01}=2552$

Juli $2002=\frac{2599}{1-0.01}=22625$

Agustus $2002=\frac{2586}{1-0.01}=2612$

\section{Perencanaan Agregat}

Sebelum dilaksanakan perencanaan agregat hal - hal yang perlu dilakukan adalah

Menentukan Kuantitas Safety Stock

Rumus penentuan jumlah Safety Stock :

$$
\begin{aligned}
& \mathrm{SS}=\mathrm{k} . \sigma \\
& \sigma=\sqrt{\frac{\sum(x-\bar{x})^{2}}{n-1}}
\end{aligned}
$$

Dimana :

$$
\text { SS = Safety Stock }
$$

$\mathrm{K}=$ Safety Faktor pengaman $\mathrm{tk}=$ $95 \%, \mathrm{k}=1,645$

$\sigma=$ Standart deviasi dari masing -masing type produk

$\mathrm{x}=$ Permintaan periode $\mathrm{t}$

$\dddot{x}=$ Rata - rata permintaan

$\mathrm{N}=$ Jumlah data permintaan 
Hasil perhitungan Safety Stock masing dibawah ini :

masing type produk dapat dilihat pada tabel

\section{Tabel 2}

Safety Stock masing - masing produk

\begin{tabular}{|l|c|c|c|c|c|}
\hline $\begin{array}{c}\text { Nama } \\
\text { Produk }\end{array}$ & $\begin{array}{c}\text { Total } \\
\text { Permintaan }\end{array}$ & Rata - rata Permintaan & $\begin{array}{c}\text { Standart } \\
\text { Deviasi }\end{array}$ & $\begin{array}{c}\text { Safety } \\
\text { Factor }\end{array}$ & $\begin{array}{c}\text { Safety } \\
\text { Stock }\end{array}$ \\
\hline 1.PavingStone & 125540 & 5231 & 553 & 1.645 & 910 \\
\hline 2. Tegel & 47310 & 1971 & 218 & 1.645 & 359 \\
\hline 3.Bataco & 142305 & 5929 & 702 & 1.645 & 1155 \\
\hline 4.Genteng & 21676 & 903 & 64 & 1.645 & 105 \\
\hline
\end{tabular}

\section{Cara Menghitung Standart Deviasi :}

Untuk Produk Paving Stone

$$
\begin{aligned}
\sigma & =\sqrt{\frac{(4460-5231)^{2}+(4825-5231)^{2}+\cdots \ldots \ldots \ldots . .+(5850-5230)^{2}}{24-1}} \\
& =553
\end{aligned}
$$

Mengkonversikan semua inventory akhir dan safety Stock kedalam satuan jam.

Tabel 3

\section{Hasil inventory akhir dan Safety Stock}

\begin{tabular}{|l|c|c|c|}
\hline \multicolumn{1}{|c|}{ Nama Produk } & Faktor Konversi & Inventory(jam) & Safety Stock (jam) \\
\hline 1. Paving Stone & 0.33 & 99 & 300 \\
\hline 2. Tegel & 0.25 & 63 & 90 \\
\hline 3. Bataco & 0.16 & 56 & 92 \\
\hline 4. Genteng & 0.25 & 42 & 26 \\
\hline
\end{tabular}

\section{Keterangan :}

Faktor Konversi $\quad=$ Total waktu proses produksi

Inventory awal (Io) $=$ Persediaan akhir periode lalu $\mathrm{x}$ faktor konversi

Safety Stock (It) = Safety Stock $\mathrm{x}$ faktor konversi

Tabel 4

Hasil konversi ramalan permintaan semua type produk(dalam jam)

\begin{tabular}{|l|c|c|c|c|c|}
\hline \multicolumn{1}{|c|}{ Periode } & \multicolumn{3}{|c|}{ Nama Produk } & \multirow{2}{*}{ Total } \\
\cline { 2 - 5 } & Paving Stone & Tegel & Bataco & Genteng & \\
\hline September'01 & 2027 & 580 & 1070 & 249 & 3926 \\
\hline Oktober'01 & 2028 & 577 & 1138 & 259 & 4002 \\
\hline November'01 & 2080 & 595 & 1136 & 253 & 4064 \\
\hline
\end{tabular}




\begin{tabular}{|l|c|c|c|c|c|}
\hline Desember'01 & 2080 & 592 & 1172 & 264 & 4108 \\
\hline Januari'02 & 2133 & 610 & 1170 & 258 & 4171 \\
\hline Februari'02 & 2133 & 608 & 1206 & 268 & 4215 \\
\hline Maret'02 & 2186 & 626 & 1204 & 262 & 4278 \\
\hline April02 & 2185 & 623 & 1241 & 272 & 4321 \\
\hline Mei'02 & 2239 & 641 & 1237 & 266 & 4383 \\
\hline Juni'02 & 2237 & 638 & 1275 & 277 & 4427 \\
\hline Juli'02 & 2292 & 656 & 1272 & 271 & 4491 \\
\hline Agustus'02 & 2290 & 653 & 1310 & 281 & 4534 \\
\hline jumlah & 25910 & 7399 & 14431 & 3181 & 50921 \\
\hline
\end{tabular}

Dari matriks Formulasi Agregat dengan Metode Transportasi disusun Rencana Agregat untuk 12 bulan Perencanaan

Tabel 5

Rencana Agregat dengan Jumlah Tenaga Kerja 15 orang

\begin{tabular}{|c|c|c|c|c|c|c|c|c|c|c|c|c|}
\hline Periode & 1 & 2 & 3 & 4 & 5 & 6 & 7 & 8 & 9 & 10 & 11 & 12 \\
\hline $\begin{array}{c}\text { Regular } \\
\text { Time }\end{array}$ & 2625 & 2835 & 2730 & 2730 & 2835 & 2365 & 2625 & 2730 & 3035 & 2614 & 3068 & 2835 \\
\hline Over Time & 1875 & 1620 & 1950 & 2797 & 1871 & 2415 & 2250 & 2185 & 1950 & 2415 & 2025 & 871 \\
\hline
\end{tabular}

Dari matriks Formulasi Agregat dengan Metode Transportasi didapatkan Jadwal Induk Produksi untuk 12 bulan Perencanaan

Tabel 6

Jadwal Induk Produksi untuk Jumlah Tenaga Kerja 15 orang

\begin{tabular}{|c|c|c|c|c|c|c|c|c|c|c|c|c|}
\hline Periode & $\mathbf{1}$ & $\mathbf{2}$ & $\mathbf{3}$ & $\mathbf{4}$ & $\mathbf{5}$ & $\mathbf{6}$ & $\mathbf{7}$ & $\mathbf{8}$ & $\mathbf{9}$ & $\mathbf{1 0}$ & $\mathbf{1 1}$ & $\mathbf{1 2}$ \\
\hline $\begin{array}{c}\text { Paving } \\
\text { Stone }\end{array}$ & 2327 & 2328 & 2380 & 2380 & 2433 & 2433 & 2486 & 2485 & 2539 & 2537 & 2592 & 2590 \\
\hline Tegel & 670 & 667 & 685 & 682 & 700 & 698 & 716 & 713 & 731 & 728 & 746 & 743 \\
\hline Bataco & 1255 & 1323 & 1321 & 1357 & 1355 & 1391 & 1389 & 1426 & 1422 & 1460 & 1457 & 1495 \\
\hline Genteng & 276 & 286 & 280 & 291 & 285 & 295 & 289 & 299 & 293 & 304 & 298 & 308 \\
\hline
\end{tabular}

Tabel 7

Hasil Peramalan untuk 12 Periode yang Akan Datang

\begin{tabular}{|c|c|c|c|c|}
\hline \multirow{2}{*}{ Periode } & \multicolumn{3}{|c|}{ Ramalan Permintaan } & Genteng \\
\cline { 2 - 5 } & Paving Stone & Tegel & Bataco & 986 \\
\hline Sept 2001 & 6080 & 2295 & 6620 & 1026 \\
\hline Okt 2001 & 6083 & 2286 & 7039 & 1003 \\
\hline Nov 2001 & 6240 & 2355 & 7030 & 1044 \\
\hline Des 2001 & 6240 & 2346 & 7252 & 1020 \\
\hline Jan 2002 & 6399 & 2416 & 7239 & 1061 \\
\hline Feb 2002 & 6398 & 2406 & 7465 & 1038 \\
\hline Mar 2002 & 6559 & 2477 & 7449 & \\
\hline
\end{tabular}




\begin{tabular}{|c|c|c|c|c|}
\hline Apr 2002 & 6555 & 2466 & 7678 & 1079 \\
\hline Mei 2002 & 6718 & 2538 & 7657 & 1055 \\
\hline Jun 2002 & 6712 & 2526 & 7891 & 1097 \\
\hline Jul 2002 & 6877 & 2599 & 7868 & 1072 \\
\hline Agust 2002 & 6870 & 2586 & 8104 & 1114 \\
\hline J $\boldsymbol{l} \boldsymbol{7}$ & $\mathbf{7 7 7 3 1}$ & $\mathbf{2 9 2 9 6}$ & $\mathbf{8 9 2 9 2}$ & $\mathbf{1 2 5 9 5}$ \\
\hline
\end{tabular}

\section{Penyesuaian peramalan dengan prosentase cacat produk}

Dengan prosentase cacat sebesar $1 \%$, maka didapat hasil sebagai berikut

Tabel 8

Hasil Ramalan yang Telah Disesuaikan dengan Prosentase Cacat

\begin{tabular}{|c|c|c|c|c|}
\hline \multirow{2}{*}{ Periode } & \multicolumn{3}{|c|}{ Ramalan Permintaan } \\
\cline { 2 - 5 } & Paving Stone & Tegel & Bataco & Genteng \\
\hline Sept 2001 & 6141 & 2318 & 6687 & 996 \\
\hline Okt 2001 & 6144 & 2309 & 7110 & 1036 \\
\hline Nov 2001 & 6303 & 2379 & 7101 & 1013 \\
\hline Des 2001 & 6303 & 2370 & 7325 & 1055 \\
\hline Jan 2002 & 6464 & 2440 & 7312 & 1030 \\
\hline Feb 2002 & 6463 & 2430 & 7540 & 1072 \\
\hline Mar 2002 & 6625 & 2502 & 7524 & 1048 \\
\hline Apr 2002 & 6621 & 2491 & 7756 & 1090 \\
\hline Mei 2002 & 6786 & 2564 & 7734 & 1066 \\
\hline Jun 2002 & 6786 & 2552 & 7971 & 1108 \\
\hline Jul 2002 & 6946 & 2625 & 7947 & 1083 \\
\hline Agust 2002 & 6939 & 2612 & 8186 & 1125 \\
\hline Jml & 78521 & 29592 & 90193 & 12722 \\
\hline
\end{tabular}

\section{Rencana Agregat}

Setelah melakukan beberapa tahapan - tahapan maka dihasilkan rencana agregat sebagai berikut.

Tabel 9

Rencana Agregat periode September 2001-Agustus 2002 Untuk tenaga kerja 23 orang

\begin{tabular}{|c|c|c|c|c|c|c|}
\hline \multirow[t]{2}{*}{ Periode } & \multirow[t]{2}{*}{ Permintaan } & \multirow[t]{2}{*}{ Inventory } & \multirow{2}{*}{$\sum_{\text {kerja }}$ hari } & \multicolumn{2}{|c|}{ Produksi } & \multirow{2}{*}{$\begin{array}{c}\text { Total } \\
\text { Produksi }\end{array}$} \\
\hline & & & & Regular & Overtime & \\
\hline 0 & & 260 & & & & \\
\hline 1 & 4527 & 602 & 25 & 4025 & 243 & 4527 \\
\hline 2 & 4604 & 602 & 27 & 4347 & 257 & 4604 \\
\hline 3 & 4666 & 602 & 26 & 4186 & 480 & 4666 \\
\hline 4 & 4710 & 602 & 26 & 4186 & 524 & 4710 \\
\hline 5 & 4773 & 602 & 27 & 4347 & 482 & 4829 \\
\hline 6 & 4817 & 602 & 23 & 3703 & 1058 & 4761 \\
\hline 7 & 4880 & 602 & 25 & 4025 & 855 & 4880 \\
\hline 8 & 4923 & 602 & 26 & 4186 & 798 & 4923 \\
\hline 9 & 4985 & 602 & 26 & 4186 & 799 & 4985 \\
\hline 10 & 5029 & 602 & 24 & 3864 & 1104 & 5029 \\
\hline 11 & 5093 & 602 & 27 & 4347 & 746 & 5093 \\
\hline 12 & 5136 & 602 & 27 & 4347 & 789 & 5136 \\
\hline
\end{tabular}




\section{Jadwal Induk Produksi}

Berdasarkan pada pengembangan model Transportasi, maka didapatkan Jadwal Induk
Produksi untuk tiap -tiap produk adalah sebagai berikut :

Tabel 10

Jadwal Induk Produksi (dalam satuan Jam)

\begin{tabular}{|l|c|c|c|c|}
\hline \multirow{2}{*}{ Periode } & \multicolumn{4}{|c|}{ Nama Produk } \\
\cline { 2 - 4 } & Paving Stene & Tegel & Bataco & Genteng \\
\hline Sept 2001 & 2327 & 670 & 1255 & 276 \\
\hline Okt 2001 & 2328 & 667 & 1323 & 286 \\
\hline Nov 2001 & 2380 & 685 & 1321 & 280 \\
\hline Des 2001 & 2380 & 682 & 1357 & 291 \\
\hline Jan 2002 & 2433 & 700 & 1355 & 285 \\
\hline Feb 2002 & 2433 & 698 & 1391 & 295 \\
\hline Mar 2002 & 2486 & 716 & 1389 & 289 \\
\hline Apr 2002 & 2485 & 713 & 1426 & 299 \\
\hline Mei 2002 & 2539 & 731 & 1422 & 293 \\
\hline Jun 2002 & 2537 & 728 & 1460 & 304 \\
\hline Jul 2002 & 2592 & 746 & 1457 & 298 \\
\hline Agust 2002 & 2590 & 743 & 1495 & 308 \\
\hline
\end{tabular}

Sebelumnya penulis juga menghitung total biaya yang harus dikeluarkan perusahaan jika menggunakan metode lama tanpa transportasi, setelah itu penulis melakukan perbandingan antara kondisi lama dengan metode tranportasi diperusahaan dan melakukan perencanaan produksi dengan metode Tranportasi maka didapatkan total biaya sebagai berikut :

\begin{tabular}{|c|c|}
\cline { 2 - 2 } \multicolumn{1}{c|}{} & Total Biaya \\
\hline Kondisi lama & Rp.171.055.500 \\
\hline Kondisi lama dengan Metode Transportasi & Rp.165.649.984 \\
\hline Kondisi baru dengan Metode Transportasi & Rp. 153.033 .472 \\
\hline
\end{tabular}

* Penghematan dari Kondisi lama terhadap kondisi baru

$$
\begin{aligned}
& =\text { Rp. } 171.055 .500-\text { Rp. } 153.033 .472 \\
& =\text { Rp. } 18.022 .028
\end{aligned}
$$

atau setara dengan

$$
\frac{R p \cdot 18.022 .028}{171.055 .500} \times 100=11 \%
$$

* Penghematan dari kondisi lama dengan transportasi terhadap kondisi baru $=$ Rp. $165.649 .984-$ Rp. 153.033.472 $=\mathrm{Rp} \cdot 12.615 .512$

atau setara dengan

$$
\frac{R p .12 .615 .512}{165.649 .984} \times 100=8 \%
$$




\section{KESIMPULAN}

Berdasarkan datą - data yang diperoleh dari hasil pengolahan data serta pembahasan pada bab v maka dapat diambil kesimpulan sebagai berikut :

1. Ramalan permintaan untuk bulan September 2001 sampai dengan Bulan Agustus 2002 adalah sebagai berikut :
Produk Paving Stone : 77731, Produk

Tegel : 29296, Produk Bataco : 89292

Produk Genteng : 12595

2. Jumlah tenaga kerja dengan biaya minimum pada prencanaan produksi periode mendatang sebanyak 23 orang dengan biaya Rp.128.682.976

3. Perencanaan agegat dengan menggunakan metode Transportasi memberikan hasil :

\section{Tabel 11}

Jumlah Tenaga Kerja yang diperlukan tiap periode (dalam orang)

\begin{tabular}{|c|c|c|c|c|c|c|c|c|c|c|c|c|}
\hline \multirow[b]{2}{*}{ Periode } & \multicolumn{4}{|c|}{2001} & \multicolumn{8}{|c|}{2002} \\
\hline & 9 & 10 & 11 & 12 & 1 & 2 & 3 & 4 & 5 & 6 & 7 & 8 \\
\hline $\begin{array}{l}\text { Reguler } \\
\text { Time }\end{array}$ & 23 & 23 & 23 & 23 & 23 & 23 & 23 & 23 & 23 & 23 & 23 & 23 \\
\hline $\begin{array}{l}\text { Over } \\
\text { Time }\end{array}$ & 5 & $5 \quad 1$ & 9 & 10 & 9 & 23 & 17 & 15 & 15 & 23 & 13 & 15 \\
\hline
\end{tabular}

4. Jadwal Induk Produksi untuk 12 periode (dalam Unit)

\begin{tabular}{|l|c|c|c|c|}
\hline \multicolumn{1}{|c|}{ Periode } & Paving & Tegel & Bataco & 1104 \\
\hline Sept 2001 & 7025 & 2680 & 7844 & 1144 \\
\hline Okt 2001 & 7055 & 2668 & 8269 & 1120 \\
\hline Nov 2001 & 7212 & 2740 & 8256 & 1164 \\
\hline Des 2001 & 7212 & 2728 & 8481 & 1140 \\
\hline Jan 2001 & 7373 & 2800 & 8467 & 1180 \\
\hline Feb 2001 & 7373 & 2792 & 8694 & 1156 \\
\hline Mar 2001 & 7533 & 2864 & 8681 & 1196 \\
\hline Apr 2001 & 7330 & 2852 & 8913 & 1172 \\
\hline Mei 2001 & 7693 & 2924 & 8888 & 1192 \\
\hline Jun 2001 & 7688 & 2918 & 9125 & 1232 \\
\hline Jul 2001 & 7855 & 2984 & 9106 & 9344 \\
\hline Agust 2001 & 7848 & 2972 & & \\
\hline
\end{tabular}

5. setelah dilaksanakan perencanaan DAFTAR PUSTAKA produksi total penghematan $\mathrm{Rp}$. 18.022.028 atau setara dengan $11 \%$ dibandingkan dengan metode lama

Amirin , Tatang M, 1989, Pokok-Pokok

Teori Sistem, Rajawali Jakarta

Ratnawati, 1999, Optimasi Sistem

Pelayanan Pasien Pada Poli Paru 
di RSUD Dr. Soetomo Surabaya

Dengan Metode $\cdot$ Simulasi, Institut

Teknologi Surabaya

Setiawan, sandy, 1991, Simulasi Teknik

Pemrograman dan Metode

Analisis, Andy Offset Yogyakarta

Siagian P, 1987, Penelitian Operasional

Teori dan Praktek, Jakarta
Simatupang. Togar M, 1995, Teori Sistem Suatu Perspektif Teknik Industri, Andy Offset Yogyakarta

Winardi, Prof. Dr., 1989, Pengantar Teori Sistem dan Analisa Sistem, Mandar Maju

Bandung 